Discussion Paper No. 594

\title{
REDISTRIBUTION, PRODUCTION INEFFICIENCY AND DECENTRALIZED EFFICIENCY
}

\author{
Hisahiro Naito
}

September 2003

The Institute of Social and Economic Research

Osaka University

6-1 Mihogaoka, Ibaraki, Osaka 567-0047, Japan 


\title{
Redistribution, Production Inefficiency and Decentralized Efficiency
}

\author{
Hisahiro Naito *† \\ Institute of Social and Economic Research \\ Osaka University \\ and \\ Department of Economics \\ University of California Irvine
}

Current Version, March 2003

\begin{abstract}
This paper analyzes the role of production distortion for income redistribution in an international trade model. In particular, this paper examines the role of the Stolper and Samuelson effect (Stolper and Samuelson 1941) on efficient income redistribution. It first shows that production inefficiency can be a part of a Pareto-efficient tax system when there is an asymmetric information problem between the government and individuals. Second, by using the technique that Diamond and Mirrlees (1971) originally developed, this paper shows that such production inefficiency is not only Pareto-improving for a small country but also essential to achieve world-wide Pareto-efficient allocation. Those two results suggest important policy implications for commercial policies.
\end{abstract}

JEL Classification Number:H21 F13

${ }^{*}$ Previous versions of this paper were circulated with various titles in several places. The first part of the work is based on Naito (1996) and the second part is based on Naito (1998). I am most grateful to my adviser, Roger H. Gordon for his helpful advice. I also appreciate comments from seminar participants in Michigan, MIT, Tilburg, Syracuse, Simon-Fraser, and Stanford Institute of Theoretical Economics Summer Workshop 2000. I also appreciate anonymous referees and the editor, Robin Boadway, who provided useful comments on the previous draft. Of course, the responsibility of all remaining errors is mine.

${ }^{\dagger}$ Address: Institute of Social and Economic Research, Osaka University, Mihogaoka 6-1, Ibaraki City, Osaka, Japan, postal code 567-0047

phone:81-6-6879-8581; fax: 81-6-6878-2766.

e-mail address: naito@iser.osaka-u.ac.jp 


\section{Introduction}

Production distortion in the forms of production subsidies/taxes, tariffs, export subsides can have a strong effect on income distribution in an open economy (Stolper and Samuelson 1949), and this theoretical prediction is one reason that economists have been interested in explaining the observed commercial policies from the point of economic theory. On the other hand, the literature of optimal taxation theory has consistently denied the use of those instruments for efficient income redistribution. In a seminal paper, Diamond and Mirrlees (1971) showed that, if the government has enough instruments, efficient production is optimal for income redistribution due to the following intuitive reason. Suppose that production is initially inefficient because the marginal rate of transformation (MRT) of the two industries is different due to some public policies. By the definition of inefficient production, this implies that, holding factor supply constant, it is possible to increase the production of at least one good without decreasing the production of other goods by eliminating those public policies and making MRTs of those industries equal. If the government has enough policy instruments, it can distribute the increased production of the goods to consumers, which results in Pareto-improvement. Thus, efficient production must be optimal. In a small open economy, an international price line is another transformation curve. Therefore, the Diamond and Mirrlees's result implies that the government should not use tariffs, production taxes or production subsidies, and further that the government should not take advantage of the Stolper-Samuelson effect of tariffs and production subsidies for income redistribution. ${ }^{1}$

However, in reality, production distortions exist. Production distortions in the form of trade barriers and non-trade barriers are persistent in both developed and developing countries even after a long negotiation to eliminate them. Why do countries use such seemingly inefficient policies contrary to the forecast of economic theory?

Political consideration might explain this inconsistency. ${ }^{2}$ On the other hand, since most political economy models assume an incumbent politician puts some positive weight on a social welfare function, it is useful to know whether a traditional approach alone can explain the use of inefficient production.

\footnotetext{
${ }^{1}$ For a formal proof of this proposition, see Dixit (1985).

${ }^{2}$ For comprehensive discussion on these lines of approach, see Rodrick (1995).
} 
The present paper shows that if an asymmetric information problem between the government and individuals is introduced in a reasonable way, inefficient production is a part of Pareto-efficient policies. To illustrate, consider a situation where the government is engaged in redistributing income, through all possible policy instruments, from skilled (high-wage) workers to unskilled (low-wage) workers under efficient production. Suppose that the government subsidies an unskilled-labor-intensive sector by introducing a production subsidy. This implies that the wage of the unskilled (skilled) will increase (decrease). If the income tax system does not change, such a subsidy does not Pareto-improve welfare. However, since the wage differential between the skilled and the unskilled becomes smaller, the government can redesign the income tax system so that the unskilled are willing to work more while giving the same utility as before. As a result, the tax burden of the skilled can be reduced. Furthermore, starting from efficient production, the distortionary effect of the subsidy on production is of secondorder magnitude while the effect to reduce the incentive problem of the income tax system is of first-order importance. Thus, introducing production distortion can Pareto-improve welfare.

However, this is not the end of our story. Now consider what will happen in the world economy. One reason that efficient production has been recommended in the previous literature is that if the MRT of each country is equated to the international price ratio, world-wide production also becomes efficient. Thus, if each country distorts its production away from the international price ratio in a decentralized way, it is very likely that the MRTs will be different among those countries because different countries have different social welfare functions, initial endowments and technologies and because they provide different rates of subsidies. Thus, one might think that although it is desirable for a small open country to distort its domestic production it is not desirable from the world-wide point of view and that it is possible to Pareto-improve the decentralized equilibrium by coordinating tax policies of all countries and equating MRTs of all production.

Even if the world-wide production happens to be efficient, there might be another externality among countries. Suppose that each government is redistributing income from the unskilled to the skilled by a non-linear income tax system in a small open economy. The above discussion shows that it is Pareto-improving for each country to subsidize an unskilled-labor-intensive sector for a given international price. On the other hand, if every government subsidizes the 
unskilled-labor-intensive sector, then the world-wide production of the unskilled-labor-intensive good will increase and, as a result, the price of the unskilled-labor-intensive good will decrease. This implies that the wage of unskilled labor will decrease. Since each country does not take the effect of its tax policy on the international price into consideration in a small open economy, one might wish to ask whether it might be possible to Pareto-improve welfare by coordinating tax policies of all governments.

This paper will show, however, that if each government can distort its production without restriction given the international prices, the decentralized equilibrium is a tax-constrained Pareto-efficient allocation from a world-wide point of view. ${ }^{3}$ In other words, from the decentralized equilibrium, no country cannot Pareto-improve the welfare of citizens of its own country by coordinating tax policies with other countries. This implies that there is no gain from international policy coordination and that inefficient production of each country is not only Pareto-improving for a small open country, but also essential to achieve world-wide taxconstrained Pareto-efficient allocation.

Those two results have important policy implications not only for a small country but also for international organizations such as WTO; I will discuss them in more in section 5.

\section{The Model}

\subsection{Basic assumptions}

Given our interest in the relationship between efficient income redistribution and production distortion in a small open economy, it is necessary to modify some of the standard assumptions in international trade theory. First, because we are concerned with the incentive problems of income redistribution, we assume that factor supply is endogenous; exogenous factor supply eliminates incentive problems. Second, because we want to consider the case where perfect income transfer is not possible, we need to assume that the government cannot identify individual types; ${ }^{4}$ if the government can identify whether each individual is a skilled or unskilled worker, then perfect income transfer is possible by means of differential lump-sum taxes and transfers.

\footnotetext{
${ }^{3}$ The definition of a tax-constrained Pareto-efficient allocation is a tax system and an allocation that cannot be Pareto-improved by changing that tax policy.

${ }^{4}$ Those two assumptions are standard in the literature of optimal non-linear income taxation.
} 
The basic model is an extension of Stiglitz (1982). There are two countries, A and B, two agent types, two goods and two factors in the world economy. $p_{h}^{*}$ is the international price of good $h(h=1,2)$. For the analysis of the decentralized equilibrium, we assume that $p_{h}^{*}$ is fixed. Following Gordon and Levinsohn (1990), we assume, without loss of generality, that there is no commodity tax and production subsidy on good 1. Further, we assume that the government imposes only a (non-linear) commodity tax, and a production subsidy on good 2 because if the government can impose a commodity tax, a production subsidy, and a tariff, one of them is redundant.

\subsection{Consumers and income taxes}

In country $k(k=A, B)$, there are two types of workers: skilled workers, denoted by superscript $s$ and unskilled workers, denoted by superscript $u$. The population of each type in country $k$ is $N^{s k}$ and $N^{u k}$, respectively. Let $\left(c_{1}^{i k}, c_{2}^{i k}, l^{i k}\right)$ be consumption of $\operatorname{good} 1$, good 2 , and the labor supply of worker $i(i=s, u)$. Let $u^{i k}\left(c_{1}^{i k}, c_{2}^{i k}, l^{i k}\right)$ be a utility function of type $i$ worker in country $k$. We assume that the utility functions of both types are the same within each country but can be different between two countries and that they are strictly quasi-concave with respect to $\left(c_{1}^{i k}, c_{2}^{i k}, l^{i k}\right)$. We assume that both goods and leisure are normal. ${ }^{5}$

The objective of the government of each country is to design a tax system to achieve a tax-constrained Pareto-efficient allocation. A tax-constrained Pareto-efficient allocation is a tax system and an allocation that cannot be Pareto-improved by changing that tax system. We assume that the government observes only total income and cannot observe workers' types. Because there are only two types of workers in this economy, at most only two points on the tax schedule will be selected by workers. Therefore, we do not lose any generality by focusing on only those two points. Invoking "the Revelation Principle," we can focus on those two points which satisfy the incentive compatible constraints.

Let $w^{i k}$ and $R^{i k}$ be the pre-tax wage rate for type $i$ labor and the wage income of type $i$ worker in country $k$. Let ICSk and ICUk be the incentive compatible constrains for the skilled

\footnotetext{
${ }^{5}$ Normality of goods and leisure is a sufficient condition for a so-called "single crossing property". A "single crossing property" plays an important role in determining the equilibrium.
} 
and the unskilled in country $k:^{6}$

$$
u^{i k}\left(c_{1}^{i k}, c_{2}^{i k}, l^{i k}\right) \geq u^{i k}\left(c_{1}^{j k}, c_{2}^{j k}, \frac{w^{j k} l^{j k}}{w^{i k}}\right),(i, j=s, u ; i \neq j ; k=A, B)
$$

The above constraints means that in each country the type $i$ worker has an incentive to work $l^{i k} \equiv \frac{R^{i k}}{w^{i k}}$, report income $R^{i k}$ truthfully and consume $\left(c_{1}^{i k}, c_{2}^{i k}\right)$ instead of mimicking the type $j$ worker, working $\frac{R^{j k}}{w^{i k}} \equiv \frac{w^{j k} l^{j k}}{w^{i k}}$, reporting income $R^{j k}$ and consuming $\left(c_{1}^{j k}, c_{2}^{j k}\right)$. Those incentive compatibility constraints imply that the government can impose not only a non-linear income tax but also non-linear commodity taxes. As we discuss later, it turns out that when the utility functions is weakly separable between consumption goods and labor supply, neither the nonlinear commodity tax nor the linear commodity tax is necessary. On the other hand, when the utility functions is not weakly separable, the non-linear commodity tax is optimal. Let $t^{i k}$ and $q_{2}^{i k}$ be a non-linear commodity tax and a corresponding consumer price of good 2 associated with a non-linear income tax for type $i=s, u$ worker in country $k$. Let $p_{h}^{k}, y_{h}^{k}$ and $\sigma^{k}$ be a producer price of good $\mathrm{h}$, an output of good $\mathrm{h}$ and a production subsidy rate on good 2 in country $k$, respectively. By its definition, $p_{1}^{k}=p_{1}^{*}, p_{2}^{k}=p_{2}^{*}\left(1+\sigma^{k}\right), q_{1}^{k}=p_{1}^{*}$ and $q_{2}^{i k}=p_{2}^{*}\left(1+t^{i k}\right)$. The government budget constraint is

$$
\sum_{i=s, u} N^{i k}\left(w^{i k} l^{i k}-p_{1}^{*} c_{1}^{i k}-q_{2}^{i k} c_{2}^{i k}\right)-\sigma^{k} p_{2}^{*} y_{2}^{k}+\sum_{i=s, u} t^{i k} p_{2}^{*} c_{2}^{i k} \geq 0 \quad(k=A, B) .
$$

\subsection{Production and Equilibrium}

For production, we assume the standard Heckscher-Ohlin model. There are two industries, $y_{h}^{k}=F_{h}^{k}\left(L_{h}^{s k}, L_{h}^{u k}\right),(h=1,2)$, in country $k$. Each industry exhibits constant returns to scale, and the production function is concave. Industry $h$ uses both skilled labor, $L_{h}^{s k}$, and unskilled labor, $L_{h}^{u k}$, and produces $y_{h}^{k}$ units of output. Let $L^{i k}$ be the total labor endowment of type $i$ labor in country $k$. The labor market equilibrium condition for type $i$ labor in country $k$ is $L^{i k} \equiv N^{i k} l^{i k}=L_{1}^{i k}+L_{2}^{i k}$.

Given the producer prices and the factor prices, each industry maximizes its profit. We assume that industry 2 is always unskilled-labor intensive. Technologies can be different in two countries. We assume that at the equilibrium the production is diversified and two goods are always produced.

\footnotetext{
${ }^{6}$ We allow for the possibility that workers pay a negative tax, i.e., the government pays a subsidy to workers.
} 
Let $C_{h}^{k}\left(w_{s}^{k}, w_{u}^{k}\right)$ be the cost function for production of one unit of good $h$ in country $\mathrm{k}$, $(h=1,2)$. If production is diversified, wages are determined by the following two equations:

$$
C_{1}^{k}\left(w^{s k}, w^{u k}\right)=p_{1}^{k} \equiv p_{1}^{*}, C_{2}^{k}\left(w^{s k}, w^{u k}\right)=p_{2}^{k} \equiv\left(1+\sigma^{k}\right) p_{2}^{*}
$$

From the Stolper-Samuelson effect (Stolper and Samuelson, 1941), we have $\partial\left(w^{u k} / w^{s k}\right) / \partial p_{2}^{k}>$ 0 .

Next, we need to specify the relationship between the producer prices and the outputs. The factor market equilibrium conditions imply

$$
y_{1}^{k} \frac{\partial C_{1}^{k}}{\partial w^{s k}}+y_{2}^{k} \frac{\partial C_{2}^{k}}{\partial w^{s k}}=L^{s k} \text { and } y_{1}^{k} \frac{\partial C_{1}^{k}}{\partial w^{u k}}+y_{2}^{k} \frac{\partial C_{2}^{k}}{\partial w^{u k}}=L^{u k} .
$$

Although (2) can determine the output of good 1 and good 2, sometimes it is more useful to work on the production possibility frontier. Given the labor supply of skilled and unskilled workers and equilibrium conditions in the labor market, the production possibility set is uniquely determined and is strictly convex due to different factor intensity. Thus, we can write $y_{2}^{k}$ as a function of $L^{s k}, L^{u k}$ and $p_{2}^{k}: y_{2}^{k}=y_{2}^{k}\left(p_{2}^{k}, L^{s k}, L^{u k}\right)$. From the Rybcyzynski theorem, if the supply of unskilled (skilled) labor increases, then the output which intensively uses unskilled labor increases (decreases) given fixed producer prices. Thus,

$$
\frac{\partial y_{2}^{k}\left(p_{2}^{k}, L^{s k}, L^{u k}\right)}{\partial\left(L^{u k}\right)}>0, \quad \frac{\partial y_{2}^{k}\left(p_{2}^{k}, L^{s k}, L^{u k}\right)}{\partial\left(L^{s k}\right)}<0
$$

From the shape of the production possibility frontier, $\frac{\partial y_{2}^{k}\left(p_{2}^{k}, l^{s}, l^{u}\right)}{\partial p_{2}^{k}}>0$.

Finally, we need to specify equilibrium conditions. The goods market equilibrium implies

$$
N^{s k} c_{1}^{s k}+N^{u k} c_{1}^{u k}=y_{1}^{k}+m_{1}^{k}, \quad N^{s k} c_{2}^{s k}+N^{u k} c_{2}^{u k}=y_{2}^{k}+m_{2}^{k} .
$$

where $m_{h}^{k}$ is the amount of imports or exports of good $h(h=1,2)$ in country $k$. Balanced trade implies that $p_{1}^{*} m_{1}^{k}+p_{2}^{*} m_{2}^{k}=0$ for each country . From (EQGk) and the balanced trade condition, we can obtain

$$
p_{1}^{*} y_{1}^{k}+p_{2}^{*} y_{2}^{k}-N^{s k}\left(p_{1}^{*} c_{1}^{s k}+p_{2}^{*} c_{2}^{s k}\right)-N^{u k}\left(p_{1}^{*} c_{1}^{u k}+p_{2}^{*} c_{2}^{u k}\right) \geq 0
$$

From Walras' law, it is straightforward to show EQGk' and BCk are equivalent ${ }^{7}$. Thus, we focus on EQGk'.

\footnotetext{
${ }^{7}$ From the government budget condition, we have

$$
\sum_{i=s, u} N^{i k}\left(w^{i k} l^{i k}-p_{1}^{*} c_{1}^{i k}-q_{2}^{i k} c_{2}^{i k}\right)-\sigma^{k} p_{2}^{*} y_{2}^{k}+\sum_{i=s, u} t^{i k} p_{2}^{*} c_{2}^{i k}=0
$$
}




\subsection{Structure of efficient tax system for a small country}

At a tax-constrained Pareto-efficient allocation where the government uses a non-linear income tax with a non-linear commodity tax and a production subsidy, the government will choose $c_{h}^{i k}, l^{i k}$ and $\sigma^{k}$ to maximize $u^{s k}\left(c_{1}^{s k}, c_{2}^{s k}, l^{s k}\right)$ subject to ICSk, ICUk and EQGk and MUCk where MUCk is

$$
u^{u}\left(c_{1}^{u k}, c_{2}^{u k}, l^{u k}\right) \geq \bar{U}^{u k}
$$

Note that $\bar{U}^{u k}$ is a parameter to derive a utility possibility frontier.

In the optimal taxation literature, researchers often solve the government's optimization problem by assuming that the government controls the tax rates. However, as Diamond and Mirrlees (1971) showed, sometimes it is more useful to assume the government can control the quantity directly and to find the tax price later. We will use the same approach in this paper. Let $y_{1}^{k}=Y_{1}^{k}\left(y_{2}^{k}, L^{s k}, L^{u k}\right)$ be the maximum production of good 1 defined on the production possibility frontier for a given level of output of good 2, and the total supply of skilled labor and unskilled labor in country $k$. On the production possibility frontier, once the relative producer price is determined, the production of good 2 is determined and it is an increasing function of $p_{2}^{k} / p_{1}^{k}$. Also, once the relative producer price is determined, the relative factor price is determined from the zero-profit condition (1) and there is one to one relationship between the relative factor price and the relative producer price from the Stolper-Samuelson theorem. Thus, we can define the relative wage as a function of the output of good 2 , the total skilled labor and total unskilled labor : $\frac{w^{u k}}{w^{k s}}=\Psi^{k}\left(y_{2}^{k}, L^{s k}, L^{u k}\right)$. From the shape of the production possibility frontier and the Stolper-Samuelson theorem, we have $\frac{\partial \Psi^{k}}{\partial y_{2}^{k}}>0$. From the Rybcyzynski theorem and the shape of production possibility frontier, it is straightforward to figure out that $\frac{\partial \Psi^{k}}{\partial L^{s l}}>0$ ,$\frac{\partial \Psi^{k}}{\partial L^{u k}}<0 .{ }^{8}$ Given the international price of good 1 and good 2, the government of country $k$ From the perfect competition, $\sum_{i=s, u} N^{i k} w^{i k} l^{i k}=p_{1}^{*} y_{1}^{k}+p_{2} y_{2}^{k}=p_{1}^{*} y_{1}^{k}+p_{2}^{*}\left(1+\sigma^{k}\right) y_{2}^{k}$. Also note that $q_{2}^{i k} c_{2}^{i k}=$ $\sum_{i=s, u} t^{i k} p_{2}^{*} c_{2}^{i k}+\sum_{i=s, u} p_{2}^{*} c_{2}^{i k}$. Thus, we obtain EQGk.

${ }^{8}$ Holding producer price constant, increasing skilled labor will increase $y_{1}$ and will decrease $y_{2}$ from the Rybcyzynski theorem. This implies that in order to keep $y_{2}$ constant, the producer price of good 2 must be increased when skilled labor increases. From the Stolper-Samuelson theorem, it implies that the wage ratio will increase. 
chooses $\left(l^{s k}, l^{u k}, c_{1}^{s k}, c_{2}^{s k}, c_{1}^{u k}, c_{2}^{u k}, y_{2}^{k}\right)$ to solve the following programming problem:

$$
\begin{aligned}
& \max _{\left\{c_{h}^{k i}, l^{k i}, y_{2}^{k}: h=1,2: i=s, u\right\}} u^{s k}\left(c_{1}^{s k}, c_{2}^{s k}, l^{s k}\right) \\
& u^{u}\left(c_{1}^{u k}, c_{2}^{u k}, l^{u k}\right) \geq \bar{U}^{u k} \\
& u^{i k}\left(c_{1}^{i k}, c_{2}^{i k}, l^{i k}\right) \geq u^{i k}\left(c_{1}^{j k}, c_{2}^{j k}, \frac{w^{j k} l^{j k}}{w^{i k}}\right),(i, j=s, u ; i \neq j ; \quad) \\
& p_{1}^{*} y_{1}^{k}+p_{2}^{*} y_{2}^{k}-\sum_{i=s, u} N^{i k}\left(p_{1}^{*} c_{1}^{i k}+p_{2}^{*} c_{2}^{i k}\right)=0
\end{aligned}
$$

The FOCs are:

$$
\begin{aligned}
& c_{h}^{s k}: u_{h}^{s s k}+\lambda^{s k} u_{h}^{s s k}-\lambda^{u k} u_{h}^{u s k}+\lambda^{g k} p_{h}^{*} N^{s k}=0 \quad h=1,2 \\
& c_{h}^{u k}: \mu^{k} u_{h}^{u u k}-\lambda^{s k} u_{h}^{s u k}+\lambda^{u k} u_{h}^{u u k}+\lambda^{g k} p_{h}^{*} N^{s k}=0 \quad h=1,2 \\
& l^{s k}: u_{3}^{s s k}+\lambda^{s k} u_{3}^{s s k}-\lambda^{s k} u_{3}^{s u k} \frac{\partial\left(\frac{w^{u k}}{w^{s k}}\right) l^{u}}{\partial L^{s k}} N^{s k}-\lambda^{u k} u_{3}^{u s k} \frac{w^{s k}}{w^{u k}}-\lambda^{u k} u_{3}^{u s k} \frac{\partial\left(\frac{w^{s k}}{w^{u k}}\right) l^{s}}{\partial L^{s k}} N^{s k}+\lambda^{g k} \frac{\partial Y_{1}^{k}}{\partial L^{s k}} N^{s k}=0 \\
& l^{u k}: \mu^{k} u_{3}^{u}+\lambda^{u k}-\lambda^{u k} \frac{\partial\left(\frac{w^{s k}}{w^{u k}}\right) l^{u s}}{\partial L^{u k}} N^{u k}-\lambda^{s k} u_{3}^{s u k} \frac{w^{u k}}{w^{s k}}-\lambda^{s k} u_{3}^{s u k} \frac{\partial\left(\frac{w^{u k}}{w^{s k}}\right) l^{u}}{\partial L^{u k}} N^{u k}+\lambda^{g k} \frac{\partial Y_{1}^{k}}{\partial L^{u k}} N^{u k}=0 \\
& y_{2}^{k}:-\sum_{i} \lambda^{i k} u_{3}^{i j k} \frac{\partial \frac{w^{j k}}{w^{i k}}}{\partial y_{2}^{k}} l^{j k}+\lambda^{g k} p_{1}^{*} \frac{\partial Y_{1}^{k}}{\partial y_{2}^{k}}+\lambda^{g k} p_{2}^{*}=0 . \\
& i, j=s, u ; i \neq j ; h=1,2 ; k=A, B ; p_{1}^{*}=1
\end{aligned}
$$

The world economy is on the decentralized equilibrium if the world demand is equal to the world supply for given $p_{1}^{*}$ and $p_{2}^{*}$ :

$$
\begin{gathered}
\sum_{k=A, B} y_{2}^{k}-\sum_{k=A, B} \sum_{i=s, u} N^{i k} c_{2}^{i k}=0 \\
\sum_{k=A, B} Y_{1}^{k}\left(y_{2}^{k}, L^{s k}, L^{u k}\right)-\sum_{k=A, B} \sum_{i=s, u} N^{i k} c_{1}^{i k}=0 .
\end{gathered}
$$

An examination of the FOCs of $c_{h}^{s k}$ and $c_{h}^{u k}$ shows that the MRS is equal to the international price ratio if the utility function is weakly separable between consumption goods and labor supply. ${ }^{9}$ This implies that when the utility function is weakly separable between consumption goods and labor supply, the commodity tax is not necessary at all. On the other hand, when the utility function is not weakly separable between consumption goods and labor supply, the

\footnotetext{
${ }^{9}$ When the utility function is weakly-separable, it can be written as $U\left(z\left(c_{1}, c_{2}\right), l\right)$. In this case, the FOC of $c_{1}^{u k}$, for example, is $\frac{\partial z}{\partial c_{1}}\left\{\alpha^{u k} u_{1}^{u u k}-\lambda^{s k} u_{1}^{s u k}+\lambda^{u k} u_{1}^{u u k}\right\}=p_{1}^{*}$. Applying for FOC of $c_{2}^{u k}$, it is easy to show that the MRS is equal to $p_{2}^{*} / p_{1}^{*}$.
} 
non-linear commodity taxes are needed and whether the relative consumer price of good 2 is greater than the relative international price of good $2, p_{2}^{*} / p_{1}^{*}$, depends on whether good 2 is complementary to labor supply and on the signs of the Lagrangian multipliers of the incentive compatibility constraints. When the income tax is "redistributive" in the sense that the incentive compatibility of the skilled is binding and the incentive compatibility of the unskilled is not binding, $\lambda^{s k}>0$ and $\lambda^{u k}=0$. In this case, if the good 2 is complementary, then the relative consumer price of good 2 should be lower than the relative international price of good 2. If the good 2 is a substitute for labor supply, then the relative consumer price of good 2 should be higher than the relative international price of $\operatorname{good} 2, p_{2}^{*} / p_{1}^{*}$. As for the FOC of $y_{2}^{k}$, the MRT in country $\mathrm{k}, \partial Y_{1}^{k} / \partial y_{2}^{k}$, is greater than the relative international price of good 2 in the redistributive case. This means that the marginal cost of production of good 2 measured by good 1 is greater than the relative international price of good 2 at the equilibrium. This implies that the government provides a production subsidy on good 2 . Therefore at the presence of non-linear income taxation in a small open economy, the inefficient production is a part of the optimal tax policy contrary to conventional wisdom.

\subsection{World-wide Planned Allocation}

Since we allow the social preference, which is $\bar{U}^{k}$, the utility functions and the production functions and the population of country $k$ to be different between two countries, it is very likely that two countries will give different subsidies to sector 2 , which implies that the MRTs of two countries are different and that the world-wide production is inefficient. In this subsection, we examine whether such a decentralized equilibrium is a tax-constrained Pareto-efficient allocation from a world-wide point of view. In the world-wide controlled allocation, the world-wide social planner sets the tax system of all of the world, and transfers income among countries. We assume that the world-wide social planner can set the tax system of all countries freely and, when we assume that international income transfer is possible, he can transfer income among countries. More specifically, let $\Delta$ be the set of a world-wide tax-constrained Paretoefficient allocation with international income transfers and $\Delta^{\prime}$ be the set of a world-wide taxconstrained Pareto-efficient allocation without international income transfers. A world-wide tax-constrained Pareto-efficient allocation with international income transfer is a world-wide 
tax system and a world-wide allocation that cannot be Pareto-improved by changing that tax system with the possibility of international income transfer among countries. A world-wide taxconstrained Pareto-efficient allocation without international income transfer is a world-wide tax system and a world-wide allocation that cannot be Pareto-improved by changing that worldwide tax system when international income transfer among countries is prohibited. Thus, at the world-wide tax-constrained Pareto-efficient allocation without international income transfer, the tax revenue of each country should be equal to the expenditure of that country. Also, note that by definition, $\Delta$ is the allocation where the world-wide social planner has more policy tools and $\Delta^{\prime}$ is the allocation that the social planner has less policy tools. Clearly if the social planner cannot improve a given allocation with a potential use of international transfer, then he cannot Pareto-improve that allocation by having less policy tools. This implies that $\Delta \subset \Delta^{\prime}$. Thus, if we show that the allocation of decentralized tax policies is in $\Delta$, it immediately implies that it is impossible to Pareto-improve welfare when international income transfer is prohibited.

Let $\phi^{i k}$ be the weight on type $i$ workers in country $k$ at the world-wide tax-constrained Pareto-efficient allocation with international income transfer. Then, the world-wide tax-constrained Pareto-efficient allocation with international income transfer can be obtained by solving the following programming problem:

$$
\begin{array}{ll}
\max & \sum_{k=A, B} \sum_{i=s, u} \phi^{i k} u^{i k}\left(c_{1}^{i k}, c_{2}^{i k}, l^{i k}\right) \\
\text { s.t. } & u^{i k}\left(c_{1}^{i k}, c_{2}^{i k}, l^{i k}\right) \geq u^{i k}\left(c_{1}^{j k}, c_{2}^{j k}, \frac{w^{j k} l^{j k}}{w^{i k}}\right), \quad(i, j=s, u ; i \neq j ;) \\
& \sum_{k=A, B} y_{2}^{k}-\sum_{k=A, B} \sum_{i=s, u} N^{i k} c_{2}^{i k} \geq 0, \\
& \sum_{k=A, B} Y_{1}^{k}\left(y_{2}^{k}, L^{s k}, L^{u k}\right)-\sum_{k=A, B} \sum_{i=s, u} N^{i k} c_{1}^{i k} \geq 0
\end{array}
$$

The above programming problem deserves several comments. First, we assume that the set defined by the above constraints is a convex set. This assumption implies that the solution of the above programming problem is unique and the allocation that satisfies the FOCs is also unique. Second, in the above programming problem we ignore the world-wide government budget constraint because when WEQ1 and WEQ2 are satisfied, the world-wide government budget constraint is automatically satisfied. To illustrate, note that the word-wide government 
budget constraint is

$$
\sum_{k=A, B}\left\{\sum_{i=s, u} N^{i k}\left(w^{i k} l^{i k}-p_{1}^{*} c_{1}^{i k}-q_{2}^{i k} c_{2}^{i k}\right)-\sigma^{k} p_{2}^{*} y_{2}^{k}+\sum_{i=s, u} t^{i k} p_{2}^{*} c_{2}^{i k}\right\} \geq 0 .
$$

(3) assumes that there is income transfer among countries because (3) requires that the sum of the surplus of the government budgets of two countries is greater than zero. From the perfect competition, we have $\sum_{i=s, u} N^{i k} w^{i k} l^{i k}=p_{1}^{*} y_{1}^{k}+p_{2}^{k} y_{2}^{k}$. By using the definition of $q_{2}^{i k}$ and $p_{2}^{k}$, the left hand side of $(3)$ is

$$
p_{1}^{*}\left\{\sum_{k} y_{1}^{k}-\sum_{k} \sum_{i} c_{1}^{i k}\right\}+p_{2}^{*}\left\{\sum_{k} y_{2}^{k}-\sum_{k} \sum_{i} c_{2}^{i k}\right\}
$$

Thus, as long as WEQ1 and WEQ2 are satisfied, the world-wide government budget constraint is automatically satisfied.

Let $\widetilde{\lambda}^{i k}$ be the Lagrangian multiplier of the incentive compatibility constraint for type $i$ workers in country $k$, and $\widetilde{\gamma_{1}}$ and $\widetilde{\gamma_{2}}$ be the Lagrangian multiplier of the equilibrium constraint of good 1 and good 2, respectively. Then, we can obtain the following FOCs:

$$
\begin{gathered}
c_{h}^{i k}: \phi^{i k} u_{h}^{i i k}+\widetilde{\lambda^{i k}} u_{h}^{i i k}-\widetilde{\lambda^{j k}} u_{h}^{j i k}-\widetilde{\gamma_{h}} N^{i k}=0 . \\
l^{i k}: \phi^{i k} u_{3}^{i i k}+\widetilde{\lambda}^{i k} u_{3}^{i i k}-\widetilde{\lambda}^{i k} u_{3}^{i j k} \frac{\partial\left(\frac{w^{j k}}{w^{i k}}\right) l^{j}}{\partial L^{i k}} N^{i k}-\widetilde{\lambda}^{j k} u_{3}^{j i k} \frac{w^{i k}}{w^{j k}}-\widetilde{\lambda}^{j k} u_{3}^{j i k} \frac{\partial\left(\frac{w^{i k}}{w^{j k}}\right) l^{i}}{\partial L^{i k}} N^{i k}+\widetilde{\gamma_{1}} \frac{\partial Y_{1}^{k}}{\partial L^{i k}} N^{i k}=0 \\
y_{2}^{k}:-\sum_{i} \widetilde{\lambda}^{i k} u_{3}^{i j k} \frac{\partial \frac{w^{j k}}{\partial y_{2}^{k}}}{\partial j k}+\widetilde{\gamma_{1}} \frac{\partial Y_{1}^{k}}{\partial y_{2}^{k}}+\widetilde{\gamma_{2}}=0 . \\
i, j=s, u ; j \neq i ; k=A, B ; h=1,2
\end{gathered}
$$

Several observations can be obtained from the above FOCs. First, $\widetilde{\gamma_{h}}$ is the shadow price of good $h$. When we prove that the decentralized equilibrium is also a world-wide tax-constrained Pareto-efficient allocation, we set $\widetilde{\gamma_{h}}$ to $p_{h}^{*}$. Second, the MRTs of production of two countries are not equal unless the world coordinator gives the same weight to countries, and technologies and population of both countries are the same. This implies that world-wide Pareto-efficient allocation often entails inefficient production and it cannot be decentralized without allowing each country to distort its production. Third, if the utility function is weakly separable between consumption goods and labor supply, the MRS between two goods are equal not only within a country but also among countries and the MRS is equal to $\widetilde{\gamma}_{1} / \widetilde{\gamma}_{2}$, the ratio between the shadow 
prices of two goods. Furthermore, comparing the FOCs of the decentralized equilibrium and the coordinated allocation, we obtain the following result:

Proposition 1 Suppose that each country achieves a tax-constrained Pareto-efficient allocation for given international prices independently and it that can distort production of its own country. Then the resulting decentralized allocation is also a world-wide tax-constrained Pareto-efficient allocation. Thus, there is no room for Pareto-improvement by international policy coordination.

Proof. Notice that the Lagrangian multiplier of the resource constraint of the decentralized equilibrium, $\lambda^{g k}$, is always positive. Thus, normalize the FOCs of the decentralized equilibrium by dividing the FOCs of the decentralized equilibrium by $\lambda^{g k}$. Then, set $\phi^{i k}, \widetilde{\lambda}^{i k}$ and $\widetilde{\gamma_{h}}$ $(i=s, u ; k=A, B ; h=1,2)$ of the world-wide planned allocation as follows:

$$
\phi^{s k}=\frac{1}{\lambda^{g k}}, \phi^{u k}=\frac{\mu^{k}}{\lambda^{g k}}, \widetilde{\gamma_{h}}=p_{h}^{*}, \widetilde{\lambda}^{i k}=\frac{\lambda^{i k}}{\lambda^{g k}},(i=s, u ; h=1,2 ; k=A, B) .
$$

By comparing the FOCs of the decentralized equilibrium and the FOCs of the world-wide planned allocation, it is easy to check that the allocation of the decentralized equilibrium will also satisfy the FOCs of the world-wide planned allocation. Furthermore, by the definition of the decentralized equilibrium, the allocation of the decentralized equilibrium will satisfy ICUk, ICSk, WEQ1 and WEQ2. This implies that the allocation of the decentralized equilibrium is the world-wide tax-constrained Pareto-efficient allocation when the world-wide social planner has weight, $\phi^{s k}=\frac{1}{\lambda^{g k}}$ and $\phi^{u k}=\frac{\mu^{k}}{\lambda^{g k}}$, for the type $s$ worker and the type $u$ worker in country $k$, respectively.

The result in a decentralized equilibrium shows that production distortion is a part of a tax-constrained Pareto-efficient allocation. The proposition 2 shows that such production distortion is not only Pareto-improving for a small country, but is also essential to achieve a world-wide Pareto-efficient allocation. Without allowing a production distortion policy to each country, the world-wide Pareto-efficient allocation cannot be decentralized in general.

The basic intuition of the above proposition is along the spirit of the Diamond and Mirrlees's production efficiency theorem. The key idea of Diamond and Mirrlees production efficiency theorem is when the government can control all consumer prices, the producer prices are disconnected from the consumer prices and the consumption decision part of the optimal taxa- 
tion problem becomes independent of the production decision part. As a result, the production decision part can be chosen freely and production efficiency becomes optimal. However, when there is asymmetric information between the government and individuals in a small open economy, some factor prices cannot be controlled directly and, as a result, some of the domestic prices cannot be disconnected from the producer prices. Therefore, the production decision cannot be decentralized and the production efficiency theorem fails for a small open economy. On the other hand, the government can control all domestic prices directly or indirectly when production distortion is allowed. This implies that all domestic prices are disconnected from the international prices once production distortion is allowed. By using the exact same logic as in the Diamond-Mirrlees's production efficiency theorem, the decentralized solution become efficient from the world-wide point of view. ${ }^{10}$

At this point, one might still wonder why the world-wide social planner cannot Paretoimprove the decentralized equilibrium by setting the MRTs of two countries equal. If he sets the MRT of two countries equal, he will be able to increase at least the world-wide production of one good without decreasing the production of the other goods for a given labor supply by the definition of production inefficiency. With international income transfer, the coordinator can distribute the increased production of the good and should be able to Pareto-improve welfare. The basic reason that such coordination is not possible comes from the economic mechanism of the factor price equalization theorem in trade theory (Samuelson, 1949) and the existence of asymmetric information. The basic idea of the factor price equalization theorem is that there is a one to one relationship between the slope of the production possibility frontier and factor prices. Thus, when the world-wide social planner tries to set the MRTs of two countries equal, he must change the factor prices at least in one country and this change of the factor prices will necessarily tighten the incentive compatibility constraint. On the other hand, under the environment of asymmetric information between the government and workers, there is no other policy instrument that can affect the factor prices other than production distortion and thus, the government does not have a policy instrument to offset this adverse change of the factor prices. When the incentive compatibility constraint becomes tighter, at least one of the agents

\footnotetext{
${ }^{10}$ The referee pointed out that Bucovetsky and Wilson (1991) obtained the efficiency result of the decentralized equilibrium in a symmetric tax competition model where factor is mobile instead of goods.
} 
will become worse off. Therefore, equating MRTs cannot Pareto-improve welfare.

The proposition 1 shows a sharp contrast to the recent result by Huber (1999). He showed that the decentralized equilibrium is not world-wide Pareto-efficient in a model of tax competition where capital is perfectly mobile but goods are not mobile among countries. The basic reason that Huber obtained a result different from ours is that in his model he assumed that the government could not use a residence-based capital income tax, which is a sensible assumption in an open economy. ${ }^{11}$ However, without the residence-based capital income tax, the government cannot control the consumer price of the second period. Thus, the government cannot disconnect the consumer prices fully from international prices.

So far, we have focused on the production distortion and have not discussed the relationship between production distortion and commercial policies such as tariffs or export subsidies. However, when the utility function is not weakly separable between consumption goods and labor supply, the consumption distortion is also optimal. In such a case, the government can achieve the tax-constrained Pareto-efficient allocation by using both tariffs and non-linear commodity taxes.

\section{Relationship to Previous Literature}

In the international trade literature, Dixit and Norman $(1980,1986)$ showed that a free trade equilibrium is Pareto-superior to an autarky equilibrium even without lump-sum transfers. Their idea is that the gains from trade can be redistributed by imposing commodity taxes on all goods and factors. However, Dixit and Norman assume that the government has complete information about workers; in particular, they assume that, in an economy consisting of skilled and unskilled workers, the government can impose different tax rates on these two factors, which requires that the government be able to identify individual skill types. Because in reality the government cannot observe and verify skill types of workers, such differential taxes would not be feasible. Recently, motivated by the previous work of Naito (1996), Spector (2001)

\footnotetext{
${ }^{11}$ In an open economy, the residence-based capital income tax implies that the government needs to know how much each consumer invests in foreign countries. However, due to information problems, such a tax would be very difficult to implement in an open economy. On the other hand, in a model where goods are perfectly mobile but factors are not, all goods are consumed within the territory of each government. Thus, there will be no information problem for controlling all consumer prices.
} 
analyzed the issue of gains from trade more carefully.

In public finance literature, Diamond and Mirrlees (1971) proved that, if the government can impose commodity taxes on all goods and factors, then production efficiency is optimal even when the government is concerned with income redistribution. Since the international price is another production possibility frontier in a small open economy, the result of Diamond and Mirrlees implies that the government should keep the marginal rate of transformation equal to the international price ratio. ${ }^{12}$ However, our criticism of Dixit and Norman (1980) also applies to the result of Diamond and Mirrlees. ${ }^{13}$ Several authors showed that when the tax instruments that the government can use are limited, inefficient production is optimal (Stiglitz and Dasgupta, 1971; Wilson 1982).

Mirrlees (1971) and Stiglitz (1982) studied an optimal non-linear income tax system when the government cannot identify workers' characteristics. Using this model, Atkinson and Stiglitz (1980) showed that the consumption distortion is not optimal when the utility function is weakly separable between consumption goods and labor supply. Natio (1999) showed that when factor prices are determined endogenously in a closed economy, imposing a commodity tax is Pareto-improving in the Atkinson and Stiglitz's model and that inefficient production is also Pareto-improving. Hubber (1999) showed that in an open economy model the sourcebased capital income tax is a part of Pareto-efficient income tax in the presence of a non-linear income tax.

The efficiency result of a decentralized equilibrium in this paper is related with the tax competition literature as well. For example, see Gordon (1983), Chari and Kehoe (1990), and Bucovetsky and Wilson,(1991) and Hubber (1999). The paper closest to the present paper is that of Bucovetsky and Wilson (1991) and Hubber (1999). Hubber noticed that the decentralized equilibrium with the source-based capital income tax and a non-linear income tax is not Pareto-efficient from a world-wide point of view. On the other hand, Bucovetsky and Wilson

\footnotetext{
${ }^{12}$ For a detailed explanation, see Dixit (1985).

${ }^{13}$ Since the result of Diamond and Mirrlees (1971) is one of the fundamental results in public economics, it is useful to clarify under what conditions their result would hold. The production efficiency result holds if i) labor is homogeneous across all individuals and the difference between the rich and the poor is the difference of initial labor endowments or productivities, or ii) the government can impose different price vectors to different individuals when individuals supply different factors. Diamond and Mirrlees assumed the first case, but it is clear that this is not appropriate to address the issue related with international trade. The second case, of course, raises the problem of incentive compatibility.
} 
(1991) analyzed a model of tax competition where a factor is mobile between two countries but goods are not mobile and two countries are symmetrical. In their paper, they provided the key fundamental observation that if the government has enough policy instruments, then the government can insulate itself from the externality caused by the change of the world rate of return and that the decentralized equilibrium is Pareto-efficient from a world-wide point of view. 14

\section{Discussion and Conclusion}

In this paper, we have shown that (i) for a small country, indirect income redistribution through inefficient production such as production taxes/subsidies is a part of the tax-constrained Paretoefficient allocation, (ii) the decentralized equilibrium is Pareto-efficient from the world-wide point of view and production distortion is essential to achieve world-wide Pareto-efficient allocation.

Those results have several policy implications. First, recent incidents in the US show that there are still some groups which feel that the globalization of the economy and removing domestic barriers of international trade will threaten their lives. This paper shows that such concern is not unfounded. When income redistribution is incomplete due to an asymmetric information problem between the government and individuals, production distortion will play an important role.

Second, in recent years there is some discussion among policy makers and economists about to what extent international organizations such as WTO should intervene domestic tax policies and commercial policies such as labor standards, domestic production subsidies, and minimum wage. For example, one might ask whether or not an international organization should recommend each country to remove its domestic subsidies targeted to particular industries in order to make the world-wide production efficient. This paper shows that as long as each county behaves as a price-taker and maximizes the welfare of its own country, the international coordination is not necessary. This result indicates that a recent trend in international organization to restrict domestic commercial policy and tax policies can be harmful to participating countries. Third, this paper indicates that the standard argument of the gains from trade needs to be modified,

\footnotetext{
${ }^{14} \mathrm{I}$ appreciate the referee for letting us know about the contribution of Bucovetsky and Wilson (1991).
} 
as I discussed in the introduction. If income redistribution is incomplete due to an asymmetric information problem, then it might be possible that a country cannot gain from trade. ${ }^{15}$

There are several issues which should be explored in future. One of those issues is to endogenize human capital accumulation. It is interesting to know whether our result would hold when human capital accumulation is endogenized but there still exists an asymmetric information problem between the government and individuals. ${ }^{16}$

Another issue that needs to be examined is the relationship between decentralized efficiency and federal tax systems. Although proposition 1 suggests that decentralized efficiency might hold in a federal tax system, there is one significant difference. In a federal tax system, all goods and workers are mobile, while workers are not mobile but goods are mobile in an open economy. Although the $\mathrm{H}-\mathrm{O}$ model suggests that importing a good is equivalent to importing factors which are used to produce that good, the characteristics and policy implications of the optimal federal tax system need to be examined further in future.

\section{References}

[1] Atkinson, A. and Joseph E. Stiglitz Lectures on Public Economics , McGraw Hill, 1980.

[2] Atkinson, A. and Stiglitz, Joseph E., "The Design of Tax Structure: Direct versus Indirect Taxation," Journal of Public Economics 6, July-Aug. 1976, pp 55-75.

[3] Bucovetsky, Sam and John Douglas Wilson, 1991, "Tax Competition with Two Tax Instruments,"Regional Science and Urban Economics, 21,pp333-350.

[4] Chari V.V. and Kehoe, Patrick J., 1990, "International Coordination of Fiscal Policy in Limiting Economies", Journal of Political Economy, 98, pp617-636.

[5] Diamond, Peter and James Mirrlees, 1971, "Optimal Taxation and Public Production," American Economic Review, 61, pp8-27 and pp 261-278.

\footnotetext{
${ }^{15}$ Recently, Guesnerie (2001) suggested this line of research, motivated by the previous works by Naito (1996) and Spector (2001).

${ }^{16}$ Recently, Saez (2001) and Naito (2002) analyzed a similar issue. Both authors studied whether the production efficiency theorem holds when human capital accumulation is endogenous. Saez (2001) argued that the previous results of Naito do not hold when human capital is endogenous. Naito (2002) showed that when different types of individuals have different comparative advantage in accumulating different types of skill, the production efficiency theorem and the Atkinson and Stiglitz's theorem do not hold.
} 
[6] Dixit, Avinash, 1985, "Tax Policy in Open Economies", Auerbach, Alan and Martin Feldstein eds., Handbook of Public Economics

[7] Dixit,Avinash K. and Norman, Victor, 1986, " Gains from Trade without Lump-Sum Compensation," Journal of International Economics, 21, August ,pp 111-22.

[8] Dixit, Avinash K. and Victor Norman, 1980, Theory of International Trade : A Dual, General Equilibrium Approach , Cambridge University

[9] Gordon, Roger H. and James Levinsohn, 1990 "The Linkage between Domestic Taxes and Border Taxes", Razin,Assaf Slemrod,Joel, eds., Taxation in the Global Economy. A National Bureau of Economic Research Project Report, Chicago and London: University of Chicago Press.

[10] Guesnerie,Roger, 2001, "Second Best Redistributive Policies: The Case of International Trade", Journal of Public Economic Theory, January, 3(1), pp15-25.

[11] Huber, Bernd, 1999, "Tax Competition and Tax Coordination in an Optimum Income Tax Model" Journal of Public Economics, March, 71(3), pp441-58.

[12] Mirrlees, James A.,1971, "An Exploration in the Theory of Optimum Income Taxation," Review of Economic Studies, 38, pp 175-208.

[13] Naito, Hisahiro, 1996, "Tariff As A Device to Relax the Incentive Problem of a Progressive Income Tax System," Research Seminar of International Economics Working Papers, No 391, The Department of Economics and School of Public Policy,http://www.spp.umich.edu/rsi, The University of Michigan.

[14] Naito, Hisahiro, 1998, "Do Decentralized Tax Policies in a Global Economy Lead to ParetoEfficient Tax System from the World Point's View?", Chapter 3, Essays on Income Redistribution and Government Policy, Ph.d dissertation, The University of Michigan.

[15] Naito, Hisahiro, 1999, "Re-examination of Uniform Commodity Taxes under A Non-linear Income Tax System and Its Implication for Production Efficiency," February 1(2),. Journal of Public Economics, pp65-88 
[16] Naito, Hisahiro, 2002, "Endogenous Human Capital Accumulation, Comparative Advantage and Direct vs. Indirect Redistribution", working paper, Osaka University

[17] Rodrik, Dani, 1995, "Political Economy of Trade Policy," Gene M. Grossman and Kenneth Rogoff eds., Handbook of International Economics, Vol 3

[18] Razin A. and E. Sadka, 1991, International Tax Competition and Gains from Tax Harmonization, Economics-Letters, 37(1), pp 69-76.

[19] Stiglitz,Joseph, 1982, "Self-Selection and Pareto Efficient Taxation," Journal of Public Economics, 17, pp 213-240.

[20] Stiglitz, Joseph E. and Partha Dasgupta, 1972, "On Optimal Taxation and Public Production," Review-of-Economic-Studies January, 39(1), pp87-103.

[21] Samuelson, Paul A., 1949, "International Factor-Price Equalisation Once Again", The Economic Journal, pp 181-197.

[22] Spector David, 2001, "Is it Possible to Redistribute the Gains from Trade Using Income Taxation?," Journal of International Economics, December, 55(2) pp441-60.

[23] Saez, Emanuel, 2000, "Optimal Taxation, Production Efficiency and Tariffs: Short-run versus Long-run", Working Paper, Department of Economics, forthcoming Jounal of Public Economics

[24] Stolper, Wolfgang and Paul Samuelson, 1941, "Protection and Real Wages," Review of Economic Studies, 9, pp 58-73.

[25] Wislon, John D., 1982, "The Optimal Public Employment Policy", Journal of Public Economics, Vol 17 No 2 March 